\section{Cost of treatment as a barrier to access and continuity of healthcare for patients with mental ill-health in Lagos, Nigeria}

\author{
Olufemi B. Olugbile, ${ }^{1}$ Ayodele O. Coker, \\ Mathew P. Zachariah ${ }^{2}$ \\ 'Department of Psychiatry, Lagos State \\ University Teaching Hospital, Ikeja; \\ 2Department of Behavioural Medicine, \\ Lagos State University College of \\ Medicine, Ikeja, Nigeria
}

\section{Abstract}

In Nigeria, there are several barriers to access to effective mental healthcare, e.g. cost, distance to the mental health facility, social stigma, cultural beliefs, attitudes and taboos. This study aimed at i) determining the cost of treatment of a random sample of psychiatric patients and to compare the sample with a matched group of patients from the internal medical department clinics; ii) assessing the impact of cost on access to care and maintenance treatment for the study group in the context of their exclusion from the Lagos State free health services and the National Health Insurance Scheme. Medical records of 100 patients currently attending the outpatients' clinic of the Department of Psychiatry of the Lagos State University Teaching Hospital (Ikeja, Nigeria) were randomly selected and audited. A similar exercise was also conducted for patients attending the medical outpatients' clinic in the same hospital. The monthly costs of prescribed medications were computed and compared. The monthly cost of treatment of patients from the Department of Psychiatry compared to patients with physical ailments from the medical outpatients' clinic was found to be significant vis à vis the average income of average Nigerians. Contrary to expectations, the mean cost of drug treatment borne by medical outpatients was much higher $(\mathrm{N}=2549.07$ vs $\mathrm{N}=1904.5)(\mathrm{P}<0.05)$ than that of patients attending the psychiatric outpatients' clinic. However, the expensive cost for the psychiatric patients far exceeded the expensive costs for the medical patients. The findings from this study showed that the average monthly cost of treatment of patients attending the psychiatric clinic was lower than patients from the medical outpatients' clinic. However, the most expensive cost for psychiatric patients far exceeded the most expensive cost for medical patients. This study also revealed that there is no free health program covering psychiatric treatment anywhere in Nigeria and mental health drugs are funded from personal and family expenses. It is thereby suggested that policy makers should change policy regarding the coverage of Nigerians with mental illness. In doing so, the major barrier to assess and the treatment gap can be reduced.

\section{Introduction}

Recent evidence showed that mental illnesses are among the most disabling illnesses globally. These reports also showed that more than half of all people with serious mental disorders are not receiving treatment and the situation is even worse in low and middle-income countries (LAMICs). ${ }^{1,2}$ The reviewed literature also indicated that the prevalence of mental disorders varied from $26.4 \%$ in USA, $17.6 \%$ in UK, $31 \%$ in Colombia and $12.1 \%$ in Nigeria. ${ }^{3,4}$ In the same vein, evidence derived from past studies indicated that in LAMIC mental health disorders are highly prevalent and disabling and sufferers of mental health disorders are not likely to patronize the few available mental health hospitals for assistance., ${ }^{4,5}$

Many studies have also demonstrated that among the several major impediments to the provision of quality mental health in LAMICs are the lack of adequate mental health facilities, insufficient human resources and poor funding for increasing mental health services. ${ }^{1,6,7}$ In Nigeria, there is little acknowledgement of mental illness at the primary health care level, which is run by the local government. Local studies have shown that doctors at primary care levels show little interest or aptitude for diagnosing mental disorder or carrying out interventions. ${ }^{4,8-11}$ Other identified factors preventing access to mental health care by patients in LAMICs include cultural perception about the nature and origin of mental disorder, social stigma attached to mental illness and the logistics of travelling long distances to the few general hospitals with psychiatric facilities or specialist psychiatric hospitals. ${ }^{14,6,8,9}$

However, the most reported important barrier to mental health care is finance.$^{1,4,6,8,9}$ In a country such as Nigeria and many other subSaharan countries, evidence shows that about $45 \%$ to $60 \%$ of the population lives below the poverty line. ${ }^{12}$ Therefore, it stands to reason that if individuals suffering from mental disorders in LAMICs cannot relatively afford quality mental health care, it is expected that governments from these countries should provide free mental health care services or subsidize the cost of mental health care. Previous studies from other parts of the world show that patients with mental health conditions receive special consideration to relieve the cost bur-
Correspondence: Ayodele 0. Coker, Department of Behavioural Medicine, Lagos State University College of Medicine, P.M.B. 21266, Ikeja, Nigeria. Tel./Fax: +234.8033267544.

E-mail: cokerrotimi@gmail.com

Key words: cost of treatment, barrier to access, continuity of healthcare, Nigeria.

Contributions: the authors contributed equally.

Conflict of interests: the authors declare no potential conflict of interests.

Received for publication: 20 December 2012

Revision received: 4 February 2013.

Accepted for publication: 16 February 2013.

This work is licensed under a Creative Commons Attribution 3.0 License (by-nc 3.0).

(C) Copyright O.B. Olugbile et al., 2013

Licensee PAGEPress, Italy

Healthcare in Low-resource Settings 2013; 1:e8 doi:10.4081/hls.2013.e8

den of their care. ${ }^{13,14}$ That may not be the case in Nigeria, where the National Health Insurance Scheme (NHIS) does not provide coverage for people with mental health disorders. This means that the cost of mental health treatment by patients is from personal or family expenses. The explanation for this may not be far-fetched. Mental health disorders, especially the severe forms, are regarded as problems for the society. ${ }^{11,15}$

Studies focusing on the issue of cost and access to mental health care were mostly carried out in the developed countries of the world. Manual and electronic searches of the literature showed that very little work has been carried out in sub-Saharan countries. A study on this important topic in Nigeria cannot be over-emphasised. This study, therefore, was aimed at: i) determining the cost of treatment of a random sample of psychiatric patients and compare them with a matched group of general patients from the medical department; ii) assessing the impact of cost on access to care and maintenance treatment for the study group in the context of their exclusion from the Lagos State Free Health services and the NHIS.

\section{Materials and Methods}

The study was a cross-sectional descriptive and comparative survey carried out at the Department of Psychiatry and Medicine of the Lagos State University Teaching Hospital (LASUTH) (Ikeja, Nigeria) from April to June 2010. The LASUTH is a tertiary health institu- 
tion situated in Ikeja, Local Government Area of Lagos State. It was formerly known as Ikeja General Hospital. It is a multi-disciplinary tertiary hospital and it has a total bed space of 520 beds. It has many specialists' clinics; it runs 24 hour-accident and emergency services and inpatient care services. The hospital also provides clinical services in internal medicine, general surgery, obstetrics and gynecology, community health, family medicine, radiology, clinical pathology, hematology and blood transfusion, pediatrics, psychiatry, dentistry, and orthopedics and trauma, among others. Although the hospital is a tertiary centre, it also serves as a primary, secondary and tertiary centre. For this reason, its services are affordable because consultation and other services are rendered free of charge and only prescription medicine and laboratory investigations are paid for by the patients. However, children under the age of 12 and adults above the age of 60 are not supposed to pay for their prescribed medications. Permission to carry out the study was sought from the Research and Ethics Committee of the hospital. Likewise, written informed consent was sought from every participant that took part in this study. One hundred participants attending the LASUTH outpatients' psychiatric clinic were randomly selected. The cost of prescription medication procured and used for one month was also quantified for each patient. All the recruited participants paid for their medication prescription from their personal or family expenditures. A matched group of 100 patients was also randomly selected from the internal medicine outpatients' clinic. Their prescription costs over the same period were also computed and analyzed. Participants with multiple medical or mental conditions were excluded from the study. The average national minimum monthly income in Nigeria is 18,000 Naira $(\mathrm{N})$, an equivalent of \$110 US Dollars per month. The currency used in the study is the Nigerian Naira. It has an equivalent of N160 Naira to $\$ 1$.

\section{Statistical analysis}

The data collected was analyzed with the aid of Statistical Package for Social Sciences (SPSS; version 14 windows). $\mathrm{P}<0.05$ was considered significant.

\section{Results}

One hundred psychiatric patients attending the outpatients' clinic of the LASUTH Psychiatric Department formed the study group, while another 100 patients from the internal medicine outpatients' clinic of the same hospital formed the comparison group. The findings showed that the mean cost of drug treatment borne by patients attending the medical outpatients was much higher [ $\mathrm{N}=2549.07$ (\$15.9) vs $\mathrm{N}=1904.5$ (\$11.9)] than that of patients attending the psychiatric outpatients' clinic. However, the standard deviation (SD) for the psychiatric patients was very wide (3991.3) compared to the medical patients (1904.5) as reflected in Table 1. Table 2 shows the $T$ test significance of difference between the means and it shows that there is no significant difference between the means. One observed factor was that, despite the fact that most of the psychiatric patients appeared to receive treatment at somewhat cheaper cost than the medical patients, the most expensive cost for the psychiatric patients far exceeded the most expensive costs for the medical patients.

\section{Discussion}

This study sought out to determine the cost of monthly treatment of a sample of psychiatric patients from LASUTH, to compare them with a matched group of patients from the internal medicine outpatients' clinic, and to assess the impact of cost on access to care and maintenance treatment for the psychiatric patients. The findings from this study did not detect a significantly higher cost for psychiatric treatment over treatment for patients with medical conditions. However, the top costs for a small minority of the mentally ill were observed to be much higher. The explanation for this findings could probably be due to the observed best practice within the mainstream of psychiatry which now requires that atypical antipsychotics and new generation antidepressants such as the Selective Serotonin Reuptake Inhibitors (SSRIs) are prescribed as first line medications for newly diagnosed cases of conditions such as schizophrenia, mania or severe depression. ${ }^{16-18}$ Again, the results of this study also showed that all the patients surveyed who attended the psychiatric outpatients' clinic, virtually paid for their psychiatric medications from personal and family expenditures. In Nigeria, where the poverty rate is high, access to quality mental health care is achieved by travelling long distances, which could also be disincentive to treatment. Due to the nature of mental disorders that run a long course, individual with chronic mental disorders may find it relatively difficult to continue to pay for the costs of their medications. In Lagos State and perhaps in the whole Nigeria, psychiatric patients may possibly not be getting the best possible treatment for their psychiatric illnesses and this should be evaluated by future studies. Unfortunately, this situation may remain the same until the barrier to access to good care is removed either through a comprehensive National Health Insurance Scheme or through some direct policy specifically aimed at reducing the cost of medications of people who suffer from mental illness.

However, the literature has demonstrated that changes are going on globally with regard to the funding of mental health care. ${ }^{1,4,19,20}$ The increasing emphasis on community mental health care is putting an increasing cost of burden on the healthcare provider, even in those countries with comprehensive NHIS, such as the UK. ${ }^{21}$ Nonetheless, health policy planners have the twin challenges of keeping cost to the state or managed care provider down, and ensuring that the cost issue even with the most expensive drugs does not become a major barrier to access or maintenance for patient. ${ }^{22-24}$ For example, after persistent complaints from different sectors about the marginalization of the mentally ill in the managed care system in the USA, there has recently been a lot of attention focused on how to include patients with mental health disorders without being exorbitant about cost of drug. ${ }^{25}$ The limitation of this study includes its small size. It was also carried out only in one teaching hospital in Nigeria, thus its general-

Table 1. Mean cost of drug treatment borne by psychiatric and medical outpatients.

\begin{tabular}{lccccc} 
Group & No. & Mean & SD & Min & Max \\
Psychiatry & 100 & 1796.0 & 3991.3 & 150 & 35210 \\
Medicine & 100 & 2549.07 & 1904.5 & 60 & 9080 \\
\hline SD, standard deviation; significance $=\mathrm{P}<0.05$. & & & &
\end{tabular}

Table 2. Means between the cost of medications of the two departments

$\begin{array}{lccccccc}\text { Group } & \text { No. } & \text { Mean } & \text { SD } & \text { df } & \begin{array}{c}\text { Mean } \\ \text { difference }\end{array} & \text { Significance } & \text { 2-tail } \\ \text { Psychiatry } & 100 & 1796.0 & 3991.3 & 198 & -752.47 & .09 & \text { - } \\ \text { Medicine } & 100 & 2549.07 & 1904.5 & - & - & - & \text { - }\end{array}$

$\mathrm{SD}$, standard deviation; $\mathrm{df}$, degree of freedom; significance $=\mathrm{P}<0.05$. 
ization may be difficult. However, the provision of mental health services and the supply of psychotropics to patients in all teaching hospitals in Nigeria are quite similar and if there are differences, they may be insignificant. Nonetheless, in light of these findings, it is desirable that future studies on cost of care and other barriers to mental healthcare should involve a larger multi-centred random sample.

\section{Conclusions}

This study provided evidence that the cost of care of psychiatric patients as compared to medical patients might not be significant. Findings of this study also showed that patients suffering from mental health disorders in Lagos State and Nigeria pay out-of-pocket for their medications which may eventually affect long-term compliance to their drug intake. Psychiatrists and mental health policy makers in Lagos State and Nigeria must formulate a policy that will take into consideration prescribing affordable drugregime in managing patients with psychiatric disorders which should also be determined substantially by the clinician's assessment of patients' financial ability to bear the costs of medications.

\section{References}

1. Eaton J, McCay L, Semrau M, et al. Scale up of services for mental health in lowincome and middle-income countries. Lancet 2011;378:1592-603.

2. World Health Organization. WHO world mental health surveys find mental disorders are widespread, disabling and often go untreated. Geneva: WHO ed.; 2012. Available from: http:/www.who.int/mediacentre/news/notes/2004/np14/en/index.ht $\mathrm{ml}$

3. Saraceno B, Dua T. Global mental health: the role of psychiatry. Eur Arch Psy Clin N 2009;259(Suppl 2):109-17.

4. Gureje 0, Lasebikan VO, Kola L,
Makanjuola V. Lifetime and 12-month prevalence of mental disorders in the Nigerian survey of mental health and wellbeing. B J Psychol-Gen Sect 2006;188:46571.

5. Jibril 0, Abdulmalik 0, Shehu S. Pathways to psychiatric care for children and adolescents at a tertiary facility in northern Nigeria. J Public Health Africa 2012;3:15-7.

6. Patel V. Mental health in low- and middleincome countries. Brit Med Bull 2007;81:81-96.

7. Saraceno B, van Ommeren M, Batniji R, et al. Barriers to improvement of mental health services in low-income and middleincome countries. Lancet 2007;370:116474.

8. Maguen S, Litz BT. Predictors of barriers to mental health treatment for Kosovo and Bosnia peacekeepers: a preliminary report. Mil Med 2006;171:454-8.

9. Olugbile OB, Zachariah MP, Coker AO, et al. Provisions of mental health services in Nigeria. Int Psychiatry 2008;2:27-31.

10. Lasebikan V, Ejidokun A, Coker AO. Prevalence of mental disorders and profile of disablement among primary health care service users in Lagos Island. Epidemiol Res Int 2012;2012:1-6. Available from: http:/www.hindawi.com/journals/eri/2012/ 357348/

11. Coker A0, Lasebikan V, Olugbile OB, Eaton J. Psychiatric psychosocial rehabilitation in Nigeria; what needs to be done. Nigerian J Psychiatry 2011;9:2-9.

12. Crick Lund C, Breen A, Flisher AJ, et al. Poverty and common mental disorders in low and middle income countries: a systematic review. Soc Sci Med 2010;71:51728.

13. Eaton J. Ensuring access to psychotropic medication in sub-Saharan Africa. Afr J Psychiatry 2008;191:179-81.

14. Jenkins R, Baingana F, Ahmad R, et al. Health system challenges and solutions to improving mental health outcomes. Ment Health Fam Med 2011;8:119-27.

15. Olugbile OB, Zachariah MP, Coker A0, et al. Yoruba world view as the nature of psychotic illness. Afr J Psychiatry
2009;12:149-56.

16. Stahl SM, Grady TM. High cost of use of second generation antipsychotics under California's medicaid program. Psychiat Serv 2006;57:127-9.

17. Rodríguez-Antona C, Gurwitz D, de Leon J, et al. CYP2D6 genotyping for psychiatric patients treated with risperidone: considerations for cost-effectiveness studies. Pharmacogenomics 2009;10:685-99.

18. Kendrick T, Simons, L. Cost effectiveness of referral for generic care or problemsolving treatment from community mental health Nurses, compared with use of general practitioner care for common mental disorders: a randomized controlled trial. Brit J Psychiat 2006;189:50-9.

19. World Health Organization. Mental health atlas 2011. Geneva: WHO ed.; 2012. Available from http://www.who.int/mental_health/publications/mental_health_atl as_2011/en/index.html

20. Institute of Global Mental Health. The global burden of mental health disorders, 2010. London: Institute of Global Mental Health Publ.; 2012. Available from: http://www.ucl.ac.uk/news/news-articles/1005/10052803

21. Belling R, Whittock M, McLaren S, et al. Achieving continuity of care: facilitators and barriers in community mental health teams. Implement Sci 2011;6:2-7.

22. Vazquez-Polo FJ, Negrin M. An analysis of the costs of treating schizophrenia in Spain: a hierarchical Bayesian approach. J Ment Health Policy Econ 2005;8:153-6.

23. Hickie IB, Davenport TA, Luscombe GM. Mental health expenditure in Australia: time for affirmative action. Aust NZ J Publ Heal 2006;30:119-22.

24. Chisholm D, Gureje 0, Saldivia S, et al. Schizophrenia treatment in the developing world: an interregional and multinational cost-effectiveness analysis. B World Health Organ 2008;86:542-51.

25. Sundararaman R. The US mental health delivery system infrastructure: a primer. Collingdale, PA: DIANE Publ.; 2009. 